\title{
GCU
}

Glasgow Caledonian

University

University for the Common Good

\section{The impact of drug-related death on staff who have experienced it as part of their caseload: an exploratory study}

McAuley, Andrew; Forsyth, Alasdair

Published in:

Journal of Substance Use

DOI:

$10.3109 / 14659891.2010 .487555$

Publication date:

2011

Document Version

Author accepted manuscript

Link to publication in ResearchOnline

Citation for published version (Harvard):

McAuley, A \& Forsyth, A 2011, 'The impact of drug-related death on staff who have experienced it as part of their caseload: an exploratory study', Journal of Substance Use, vol. 16, no. 1, pp. 68-78.

https://doi.org/10.3109/14659891.2010.487555

\section{General rights}

Copyright and moral rights for the publications made accessible in the public portal are retained by the authors and/or other copyright owners and it is a condition of accessing publications that users recognise and abide by the legal requirements associated with these rights.

Take down policy

If you believe that this document breaches copyright please view our takedown policy at https://edshare.gcu.ac.uk/id/eprint/5179 for details of how to contact us. 
The impact of Drug-Related Death on staff who have experienced it as part of their caseload: An exploratory study

McAuley, Andrew; MSc, Public Health Adviser, NHS Health Scotland, Public Health Science Directorate, Elphinstone House, Glasgow, G4 OBA

Forsyth, Alasdair J; PhD, Senior Research Fellow, Glasgow Centre for the Study of Violence, Glasgow Caledonian University, Cowcaddens Road, Glasgow, G4 OBA 
The impact of Drug-Related Death on staff who have experienced it as part of their caseload: An exploratory study

Introduction

Illicit drug use accounts for a range of harms and fatalities. Harm affects not just the user, but those around them too, particularly when experiencing a drug-related death (DRD). Despite much research having been carried out into DRD, this paper is the first to address its impact on an important but hitherto neglected population, specifically the impact of DRD upon addiction professionals.

Scotland has the highest recorded drug-related death (DRD) rate in the UK and this is among the highest in Europe. In 2008, the Scottish DRD rate of 10.8 per 100,000 population was considerably higher than the 3.0 per 100,000 and 2.1 per 100,000 rates found in the same year in England/Wales and Northern Ireland respectively (Davies et al, 2009). Moreover the most recent annual figures in Scotland show that DRDs are at record levels and continuing to increase with 574 recorded in 2008, an increase of $131 \%$ since 1998 (GROS, 2009a). Studies looking at trends in drug user outcomes among treatment populations have shown mortality rates of between 1 and 2\% (Gossop et al, 2002; Hickman et al, 2003; Hutchinson et al, 2000).

Being engaged in a process of treatment and care can have a positive effect on outcomes, including DRD (Davoli et al., 2007). Clients may access more than one service, though, and this can impact on more than one member of staff should they die. The national investigation into Scottish DRDs in 2003 (Zador et al., 2005) found the majority (78\%) had been in contact with services during the 6 months prior to their death and more than $50 \%$ were still in contact with at least one agency at the time of death, suggesting that many staff are potentially affected by this issue.

Background 
Previous research into DRD has targeted specific groups such as the deceased themselves (Zador et al., 2005; Darke et al., 2006), witnesses of overdose (Best et al, 2000; Davidson et al, 2002; Tracy et al, 2005) or the families of victims (Da Silva et al., 2007; Guy, 2004; Guy \& Holloway, 2007; Strang et al., 2008). These studies focussed on a range of factors from the sociodemographic profiles of the victims, reactions to the overdose situation itself and the bereavement experiences of family members in the aftermath of the event. There has been little or no research conducted, however, on staff working in the substance misuse field and the impact that DRD has had on those who have experienced it as part of their caseload.

The experiences and impact of death on other professional care-givers has been well documented over the years, particularly in nursing fields such as Paediatrics (Stack, 2003), Emergency-Care (Briysiewicsz, 2006: LeBrocq et al., 2003), Palliative-Care (Llamas et al., 2001; Newton \& Waters, 2001), Intensive-Care (Lenart et al., 1998; Pearson et al., 2001) and Long-Term Care settings (Katz et al., 2001; Rickerson et al., 2005;). Doctors have also been researched in terms of how they react to the death of a patient (Redinbaugh et al., 2003).

A range of social, emotional and physical impacts have been identified in these studies highlighting the grief and bereavement experiences that professional care-givers face following the death of their patients. However many of the deaths in these settings are expected and the conclusion of a long illness or period of suffering where staff and relatives can prepare themselves for the eventual passing. In addition, deaths in the elderly population are received easier than those in the young as they form part of a natural life-cycle which is perceived to have come to an end (Da Silva, 2007).

Many of the treatment and care providers within the addictions field are also nurses and doctors themselves but the addictions field incorporates a range of other professional caregivers from health, social work and voluntary organisations and it is unclear whether they experience similar social, physical and emotional effects when they experience DRD. 
In Scotland, DRDs feature mainly young men (GROS, 2009a) who are at an increased risk of mortality compared to their non-drug using peers, with many having experience of non-fatal overdose in the lead up their death (Zador et al., 2005). Despite this, DRDs are sudden and often unexpected, regularly involving young clients who have been progressing in treatment programmes, decreasing their tolerance and making them vulnerable to overdose should they relapse at any stage. Indeed many DRDs are caused by 'accidental overdose' related to a recent period of abstinence such as a prison sentence, detoxification or residential rehabilitation (Bird \& Hutchinson, 2003; Strang et al., 2003) and at a time when those close to the drug user may be experiencing a positive outlook on their future (Guy, 2004). Sudden deaths are more problematic to cope with and are related to more intense sadness than those which are expected after a long illness or from a natural cause (Da Silva et al., 2007; Lehman et al., 1989). This is often because DRDs create feelings of anger, disbelief, guilt and betrayal to those close to the deceased (Guy, 2004).

Studies specifically dealing with reactions to death from a drug overdose are few and mainly qualitative. Both Da Silva et al (2007) and Guy (2004) looked qualitatively at the impact that an overdose death had on the families of the victims. Participants involved both those who were aware of the drug use of their family member and those who were not. Those who were unaware experienced feelings of anger, guilt and helplessness at being unable to tackle the problem before it became too late whilst those who had a prior knowledge were identified with being prepared for such an extreme event and experiencing mixed emotions of both grief and relief when it occurred. Overall, though, the findings concluded how stressful a fatal overdose was for families and that psychological support was essential in its aftermath.

This paper will quantify the impact has DRD has upon addiction professionals who experience such events as part of their caseload.

Method 
This research was conducted in the Lanarkshire NHS health authority area in Scotland, which has a population of just over half a million people (GROS, 2009b) and an average DRD rate of 0.07 per 1000 population compared with a rate of 0.08 per 1000 population across Scotland as a whole. Ethical permission for the study was sought and granted by the local NHS Research Ethics Committee. Data was collected using self-completion questionnaires distributed to all 261 specialist addictions staff in Lanarkshire, working mainly across the health (48\%), social work (37\%) and voluntary sectors (15\%), known to have managed their own caseload within the last 5 years. This initial prospective 'recruitment' stage asked only those who had experienced DRD to respond. All completed questionnaires were returned within two months and all responses were anonymous.

The questionnaire was a survey tool previously used successfully by Rickerson et al (2005) who looked at the prevalence of grief-related reactions among long-term care staff. Other studies (e.g. Redinbaugh et al, 2003) have used validated instruments such as the grief reaction scale (Jacobs et al, 1986), impact of events scale (Horowitz et al, 1979) and the brief COPE (Carver, 1997). However these were felt to be inappropriate because they were either aimed at gauging reaction immediately or soon after the event took place (Jacobs et al, 1986) or not designed specifically to measure the impact of a death (Horowitz et al, 1979; Carver, 1997).

The questionnaire was split into three sections. The initial section asked about staff work environment, age, gender, education etc. Section two asked about the clients they work with and how those who die affect them. Staff were asked to relay their grief-related reactions to either their 'most recent' or their 'most important' DRD on their caseload. To quantify the impact this death had upon them, they were asked to identify how many grief-reactions, from a list of 22 used in a previous study (Rickerson et al, 2005), they experienced following a DRD on their caseload. Section three was primarily concerned about how staff would use support services should one of their clients suffer a DRD e.g. 'What types of information or services would you want included in ANY bereavement program you were offered?'. 
Questionnaires from respondents who had experienced DRD on their caseload were then analysed using SPPS v13.0 (SPSS Inc. 2005).

\section{Results}

A total of 76 questionnaires were returned, $65(87 \%)$ of which reported at least 1 DRD on their caseload in their career. Return rates were highest from staff working in the voluntary sector (35\%), followed by health (33\%) and social work (22\%). In addition slightly more males (33\%) than females (27\%) responded.

The 65 respondents who met the entry criteria for this exploratory study between them reported a total of 297 DRDs (mean: 4.6, SD: 4.44, 95\% CI: 3.41-5.61). On average these staff described their grief-related reactions to a death which had happened just over a year ago (mean: 13.3, SD: 14.59 , 95\% CI: 9.59-17.06).

These 65 respondents comprised 34 (52\%) who worked in the health service, 16 (25\%) in social work and $13(20 \%)$ worked in the voluntary sector. On average they have worked in the substance misuse field for over 8 years and have held their current post for $7 \frac{1}{2}$ years. More than half were female $(n=37,57 \%)$, around two-thirds were university educated $(n=44,68 \%)$ and a similar proportion were married/living with a partner $(n=43,66 \%)$. A wide range of age-groups were represented with 16 (25\%) aged 25-34, 21 (32\%) aged 3544, $22(34 \%)$ aged $45-54$ and $6(9 \%)$ aged 55 and over.

The deaths the staff described were mostly male $(49,75 \%)$, with the largest proportion aged between 25 and $34(26,40 \%)$ and perceived to have been caused accidental overdose (36, $55 \%$ ), demonstrating a similar profile to those described in the national investigation (Zador et al, 2005). Almost three-quarters of staff $(46,71 \%)$ reported that their client's death had come as a surprise to them. 
These data also indicate, on average, that staff with experience of DRD on their caseload have worked in the substance misuse field for almost $81 \frac{1}{2}$ years, held their current post for 7 $1 / 2$ years, manage a caseload size of around 41 clients and report experiencing 5 career DRDs. They were also more likely to describe a specific DRD from just over a year ago, and use 2 support sources in the aftermath.

The main area of interest was the prevalence of grief-related reactions experienced by staff following a DRD on their caseload. Staff reported experiencing a range of grief-related reactions (table 1 ) following a DRD on their caseload with the majority $(57,88 \%)$ identifying at least one reaction (mean: 3.5, range: $0-12$ ). There was little variation in mean grief-related reaction scores between sectors with voluntary organisation staff reporting slightly more (3.8) than social work (3.7) and health (3.4). The most common feeling identified by staff was sadness $(54,83 \%)$. A number of staff also reported feelings of guilt $(26,40 \%)$, anger (24, $37 \%)$ and helplessness $(17,26 \%)$ about the death of their client, whilst more than a quarter $(18,28 \%)$ had also thought about their own morbidity as a result. Physical reactions such as crying (14, 22\%) and having trouble sleeping (11, 17\%) were much less prominent.

Table 2 shows that, using independent t-tests, female staff reported significantly more griefrelated reactions following a DRD on their caseload than males $(t=2.75, d f=63, p<0.004)$. A tendency for staff who felt 'somewhat or very close' to the deceased to report more griefrelated reactions compared to those who felt 'not at all' close to their client was also indicated albeit weakly ( $t=-1.71, d f=63, p<0.046)$. This is despite women, on average, reporting less career experience of DRDs on their caseload (mean: 4.0) than men (mean: 5.2). The length of time staff had known the deceased had no significant bearing on impact.

There were no significant differences in the prevalence of grief-related reactions for staff describing a younger client ( $<35$ years-old) or an older client ( $>35$ years-old). Moreover deaths from accidental overdose which are generally unintentional and unexpected did not 
show any significantly greater prevalence of grief-related reactions in staff compared to other types of DRDs (e.g. Suicide, Chronic Drug Abuse).

Staff with greater experience of DRDs ( $>2$ deaths) in their career reported a significantly ( $t=-$ $1.70, d f=63, p<0.047)$ higher prevalence of grief-related reactions following such an event on their caseload, using an independent t-test. In addition the length of time since the DRD being described had no major impact, with those describing an event from the past year not being significantly more affected than those reflecting on an event from over a year ago. Interestingly both career experience and staff age had no significant bearing although those with more than 5 years experience did report slightly more grief-related reactions (mean: 3.8) than their more inexperienced colleagues (mean: 3.0).

Staff with larger caseloads ( $>30$ clients) described significantly more $(t=-2.25, d f=30$, $p<0.016)$ grief-related reactions than those managing smaller caseloads, using independent t-tests, hinting at the increased worry and anxiety staff face in the aftermath of one of their clients dying, particularly when faced with so many more potential victims of DRD on their caseload that they may feel unable to prevent. Indeed almost half of the sample $(32,49 \%)$ said that the DRD they were describing affected their relationships with their other clients 'somewhat or a lot'. Specifically staff with larger proportions were proportionately more likely to report anger ( $48 \%$ compared to $24 \%$ in small caseload staff), helplessness (35\% / $12 \%$ ), having trouble sleeping (26 / 6\%) and crying (29\% / 12\%).

Staff who sought more sources of support showed a significantly higher prevalence of griefrelated reactions ( $t=-3.06, d f=63, p<0.002)$ using independent $t$-tests. This was confirmed even when controlling for other factors, as detailed in Table 3, which shows a linear regression model indicating that female staff, those with access to more sources of support and the length of time since the DRD were all associated with the prevalence of grief-related reactions. 
An important additional finding was that the majority of staff said they would attend a DRD specific support group $(45,69 \%)$ or one-on-one DRD support $(42,65 \%)$ if they were offered it following a death.

\section{Discussion}

This study provides the first quantitative exploration of how DRDs impact upon staff who have experienced it as part of their own caseload. The study had its limitations. Firstly it was based on a relatively small sample size $(n=65)$ identified through the initial prospective 'recruitment' stage. The proportion of non-respondents who had experienced a DRD is unknown. Perhaps many did not respond because they had never experienced a DRD. Others may not have responded because they have not been affected by a DRD to the same extent as those who did. However the aim this exploratory study was not to assess the prevalence of DRD experienced by addiction professionals, but to see whether any were affected by such events, and if so to what extent. To this end the study succeeded in uncovering a hitherto unreported issue, one that needs to be addressed, and in light of this finding further research on validating prevalence rates is recommended. Secondly, it might be argued that the survey method used is limited to set answers, which given the sensitivity of this topic some participants may feel obliged to respond to in a certain way (e.g. by reporting grief reactions in a socially desirable manner). Future qualitative investigation would be required to assess more fully how participants rationalised these events. Thirdly, the study did not use a validated instrument to measure the prevalence of grief-related reactions for staff following a DRD on their caseload principally because there is not one available, despite an exhaustive search of the literature.

There are currently no DRD specific support mechanisms that staff in the region in which this research was conducted can access and anecdotal evidence suggests the same situation is mirrored across the Scotland. Generic counselling and bereavement services undoubtedly play an important role but may not be the best way to deal with the overall impact a DRD has on a staff member who is experiencing a whole host of grief-related-reactions as a result of a 
death on their own caseload. Indeed the majority of staff in this study said they would attend a DRD specific support service if they were offered it. Basic steps such as formalising the death notification process to staff who were known to the deceased should be initiated as a standard response. At present staff often rely on anecdotal or media reporting and it is doubtful the lack of clarity these sources provide helps the coping process (Guy, 2004). In addition, providing a debriefing session and one-to-one support, like that proposed by Redinbaugh et al (2003), on both the events leading up to death and staff feelings and emotions in its aftermath, should be available to those who need it and therefore should be considered for future policy and practice. It can also deter any notion of a 'blame culture' being developed and promote a working environment where each death can used as an opportunity to reflect and learn lessons for the benefit of future practice.

Not all staff reacted in the same way, however, and this must be taken into consideration when determining what can be done to assist them in future. Some were more affected than others such as female staff who, overall, reported more grief-related reactions than their male counterparts reflecting results from other similar studies on care-providers, gender and bereavement (Belle, 1991; Redinbaugh et al., 2003; Whitfield et al., 2002).

The most common feeling identified by staff was sadness similar to long-term care staff whom the list of grief-related reactions was used on originally (Rickerson et al., 2005). Staff who felt close to their client in some way also reported a greater prevalence of grief-related reactions which also supports findings from other studies (Redinbaugh et al., 2003; Rickerson et al., 2005). This is important as it highlights the dangers of developing a too close a bond between staff and clients which may be beneficial to their care and treatment, but adversely affects the staff-member when things go wrong. It is unlikely staff feel close to every client on their caseload but when they do they must be aware of the difficulties that can arise should something happen to them. This is a particularly interesting result to relay to staff who have yet to experience a DRD on their caseload to prepare them for what potentially could happen should it occur. Only a minority of clients in treatment will ever die from a DRD 
but it is likely that a significant proportion of these will be clients who had been 'doing well' in the lead up to their death and staff should be fully aware of the potential impact such an adverse event can have on them.

The size of staff caseload also had an effect on their reaction to the death which has implications for services operating with large numbers of clients where the potential for DRD is increased. Indeed managing a large caseload brings its own professional pressures and this study has shown that the impact of an event as serious as a DRD increased pressure through increased grief-related reactions to it. These effects can be positive such as using the event as a trigger to remind other clients about the dangers of DRD and emphasising messages around harm reduction. However they can also be negative as staff begin to question their own work practice and become over cautious with their other clients making them less likely to take 'positive risks' (e.g. moving clients from supervised prescriptions to take-home dosages).

The importance of psychological support in the aftermath of a DRD discussed by Da Silva (2007) and Guy (2004) was also hinted at in our results with staff who had access to more support sources reporting more grief-reactions. This highlights that support sources potentially provide a vehicle for staff to express their grief following a DRD on their caseload rather than 'bottling-up' their feelings. With this in mind one may think that the grief-related reactions would diminish over time but our regression model suggests otherwise with prevalence actually increasing as time increases supporting results in similar research (Rickerson et al., 2005) and theory that the impact of a DRD is "long-lasting as a result" (Guy, 2004).

Rickerson et al's (2005) finding that staff who had worked longer, and therefore experienced more death, reported greater prevalence of grief-related reactions following a death in an almost 'cumulative grief' effect is mirrored by our results. This emphasises Rickerson et al's point that staff do not appear to become more used to dealing with death and loss over time 
as one might expect. This suggests that each new death potentially stirs emotions and reactions from a similar incident in the past. Time does not, in this scenario, appear to be a great healer as the impact of such a significant event remains with staff who, in their day-today practice, face many more potential DRD victims such is the chaotic and high-risk lifestyle that problematic substance misuse carries.

The involvement of a younger person in a DRD is thought to create a stronger emotional reaction than when someone older is involved (Da Silva, 2007). Despite this, though, our study found no significant differences in prevalence of grief-reactions between staff describing a younger deceased client compared to those describing an older client. Indeed it appears that the relationship between the client and key-worker influences the reaction following a DRD more than the type of death itself, regardless of client age or length of time staff have known them.

The results of this study open up numerous avenues for future research particularly because of the scarcity of previous work in this area specific to substance misuse staff. This could include broadening the methodology out to include staff involved with clients who suffer alcohol-related deaths or suicide, two key current policy agendas in Scotland, and the impact of these tragic events.

Primarily, though, the effectiveness of this tool warrants use in further research in the DRD area. Rolling out this study's methodology to a much larger sample, incorporating substance misuse staff from both major cities and rural communities, would help glean more specific insights into the differences, if any, between staff working in geographically discrete areas, different sectors and, indeed, different roles. A larger sample would also be able to address questions around deaths from different types of substances and the impact that these may have. The issue of children could also be included in future as this study did not include any fields requesting participants childcare history and this merits future consideration, for instance do staff who are parents react differently than those who are not? Or does the 
parenting status of the deceased affect the impact on staff (Guy, 2004)? These are all worthwhile areas to explore in future studies.

\section{Conclusions}

This study has highlighted that when someone dies of a DRD it is not only the needs of friends, family or witnesses that need to be taken into account. The presence of grief-related reactions in almost $90 \%$ of this sample suggests that staff who were involved in the care and treatment of the deceased also need to be considered when dealing in the aftermath of the event.

\section{References}

Belle, D. (1991). Gender differences in the social moderators of stress. In Monat A., \& Lazarus RA., (eds.), Stress and coping: an anthology (pp. 258-74). 3rd ed, New York: Columbia University Press.

Best, D., Man, L.H., Gossop, M., Noble, A., \& Strang, J. (2000). Drug user's experience of witnessing overdose: What do they know and what do they need to know? Drug and Alcohol Review, 19, 407-412.

Bird, S., \& Hutchinson, S. (2003). Male drug-related deaths in the fortnight after release from prison: Scotland, 1996-1999. Addiction, 98, 185-190.

Brysiewicz, P. \& Uys, L.R. (2006). Model for Dealing With Sudden Death Advances in Nursing Science. Advances in Nursing Science, 29:3, E1-E11.

Carver, C.S. (1997). You want to Measure Coping but Your Protocol's Too Long: Consider the Brief COPE. International Journal of Behavioral Medicine. 4:1, 92-100. 
Darke, S., Degenhardt, L., \& Mattick, R. (2006). Mortality Amongst Illicit Drug Users: Epidemiology, Causes and Intervention. Cambridge University Press.

Da Silva, E.A., Regina Noto, A. \& Formigoni, M.L.O.S. (2007). Death by Drug Overdose: Impact on Families. Journal of Psychoactive Drugs, 39:3, 301.

Davidson, P.J., Ochoa, K.C., Hahn, J.A., Evans, J.L., \& Moss, A.R. (2002). Witnessing heroinrelated overdoses: the experiences of young injectors in San Francisco. Addiction, 97, 15111516.

Davies, C., English, L., Lodwick, A., McVeigh, J., \& Bellis, M.A. (2009). United Kingdom Drug Situation: Annual Report to the European Monitoring Centre for Drugs and Drug Addiction (EMCDDA) 2009. Department of Health.

http://www.nwph.net/ukfocalpoint/page.aspx?categoryid $=4 \& i d=8$

Davoli, M., Bargagli, A.M., Perucci, C.A. et al. (2007). Risk of fatal overdose during and after specialised drug treatment: the VEdeTTE study, a national multi-site prospective cohort study. Addiction, 102, 1954-9.

General Register office for Scotland (GROS). (2009a). Drug-related Deaths in Scotland in $2008 . \quad$ http://www.gro-scotland.gov.uk/statistics/publications-and-data/drug-relateddeaths/drug-related-deaths-in-scotland-2008/index.html

General Register office for Scotland (GROS). (2009b). Mid-2008 Population Estimates Scotland. $\quad$ http://www.gro-scotland.gov.uk/statistics/publications-and-data/populationestimates/mid-2008-population-estimates-scotland/index.html

Gossop, M., Stewart, D., Treacy, S., \& Marsden, J.A. (2002). Prospective study of mortality among drug misusers during a four-year period after seeking treatment. Addiction, 97, 39-47. 
Guy, P. (2004). Bereavement through Drug Use: Messages from Research. Practice, 16:1, 4354.

Guy, P. \& Holloway, M. (2007). Drug-related Deaths and the 'Special Deaths' of Late Modernity. Sociology, 41:83, 83-96.

Hickman, M., Carnwath, Z., Madden, P., Farrell, M., Rooney, R., Ashcroft, R., et al. (2003). Mortality and fatal overdose risk - pilot cohort study of heroin users recruited from specialist drug treatment sites in London. Journal of Urban Health, 90, 274-287.

Horowitz, M., Wilner, N. \& Alvarez, W. (1979). Impact of Event Scale: A Measure of Subjective Stress. Psychosomatic Medicine. 41:3, 209-218.

Hutchinson S.J., Taylor, A., Gruer, L., Barr, C., Mills, C., Elliott, L., et al. (2000). One-year follow-up of opiate injectors treated with oral methadone in a GP centred programme. Addiction, 95, 1055-1068.

Jacobs, S.C., Kasl, S.V., Ostfield, A.M., Berkman, L., Kosten, T.R., Charpentier, P. (1987). The measurement of grief. Hospice Journal. 2:4, 21-36.

Katz, J., Sidell, M., \& Komaromy, C. (2001). Death in homes: bereavement needs of residents, relatives and staff. Int J Palliat Nurs, 6:6, 274-279.

LeBbrocq, P., Charles, A., Chan, T., \& Buchanan, M. (2003). Establishing a bereavement program: caring for bereaved families and staff in an emergency department. Accid Emerg Nurs, $11,85-90$. 
Lehman, D.R., Lang, E.L., Wortman, C.B., \& Sorenson, S.B. (1989). Long-Term Effects of Sudden Bereavement: Marital and Parent-Child Relationships and Children's Reactions. Journal of Family Psychology, 2:3, 344-367.

Lenart, S.B., Bauer, C.G., Brighton, D.D., Johnson, J.J. \& Stringer, T.M. (1998). Grief support for nursing staff in the ICU. J Nurses Staff Dev, 14, 293-296.

Llamas, K., Llamas, M., Pickhaver, A.M., \& Piller, N.B. (2001). Provider perspectives on palliative care needs at a major teaching hospital. Palliat Med, 15, 461-470.

Newton, J., \& Waters, V. (2001). Community palliative care clinical nurse specialists' descriptions of stress in their work. Int J Palliat Nurs, 7:11, 531-540.

Pearson, A., Robertson-Malt, S., Walsh, K., \& Fitzgerald, M. (2001). Intensive care nurses' experiences of caring for brain dead organ donor patients. J Clin Nurs, 10, 132-139.

Redinbaugh, E.M., Sullivan, A.M., Block, S.D., Gadmer, N.M., Lakoma, M., Mitchell, A.M., et al. (2003). Doctors emotional reactions to recent death of a patient: a cross sectional study of hospital doctors. BMJ, Vol, 327:185.

Rickerson, E.M., Somers, C., Allen, C.M., Lewis, B., Strumpf, N., \& Casarett, D.J. (2005). How Well Are We Caring for Caregivers? Prevalence of Grief-Related Symptoms and Need for Bereavement Support Among Long-Term Care Staff. Journal of Pain and Symptom Management, 30:3, 227-233.

Stack, C.G. (2003). Bereavement in paediatric intensive care. Paediatric Anaesthesia, 13, 651654. 
Strang, J., McCambridge, J., Best, D., Beswick, T., Beam, J., Rees, S., et al. (2003). Loss of tolerance and overdose mortality following inpatient detoxification: follow up study. BMJ, 326, 959-960.

Strang, J., Manning, V., Mayet, S., Titherington, E., Offor, L., Semmler, C., et al. (2008). Family carers and the prevention of heroin overdose deaths: Unmet training need and overlooked intervention opportunity of resuscitation training and supply of naloxone. Drugs: education, prevention and policy, 15:2, 211-218.

Tracy, M., Markham-Piper, T., Ompad, D., Bucciarelli, A., Coffin, P.O., Vlahov, D., et al. (2005). Circumstances of witnessed drug overdose in New York City: implications for intervention. Drug and Alcohol Dependence, 79:2, 181-190.

Whitfield, K.E., Clark, R., Weidner, G. \& Anderson, N.B. (2002). Sociodemographic diversity and behavioural medicine. Journal of Consul Clin Psychol, 70, 463-481.

Zador, D., Kidd, B., Hutchinson, S., Taylor, A., Hickman, M., Fahey, T et al. (2005). National investigation into Drug Related Deaths in Scotland, 2003. Scottish Executive. http://www.scotland.gov.uk/Publications/2005/08/03161745/17507 
Table 1: Grief-related reactions following a DRD on a staff caseload

\begin{tabular}{|l|r|r|}
\hline Grief-related reaction & $\mathbf{n}$ & $\mathbf{\%}$ \\
\hline I have been sad & 54 & $83.1 \%$ \\
\hline I have felt guilty & 26 & $40.0 \%$ \\
\hline I have been angry & 24 & $36.9 \%$ \\
\hline I have thought about my own morbidity & 18 & $27.7 \%$ \\
\hline I have felt helpless & 17 & $26.2 \%$ \\
\hline I have cried & 14 & $21.5 \%$ \\
\hline I have been restless & 13 & $20.0 \%$ \\
\hline I have had difficulty concentrating & 12 & $18.5 \%$ \\
\hline I have had trouble sleeping & 11 & $16.9 \%$ \\
\hline I have been anxious & 10 & $15.4 \%$ \\
\hline I have dreamed about a client who has died & 9 & $13.8 \%$ \\
\hline Other & 8 & $12.3 \%$ \\
\hline I have been irritable & 5 & $7.7 \%$ \\
\hline I have felt that a client is not really dead & 4 & $6.2 \%$ \\
\hline I have expected to see a client who has died during my daily routine & 4 & $6.2 \%$ \\
\hline I have had a change in appetite & 3 & $4.6 \%$ \\
\hline I have thought that I saw a client who had died & 3 & $4.6 \%$ \\
\hline I have had mood swings & 2 & $3.1 \%$ \\
\hline I have had less energy & 2 & $3.1 \%$ \\
\hline I have withdrawn from social activities & 2 & $3.1 \%$ \\
\hline I have been unable to accept the death of a client & 1 & $1.5 \%$ \\
\hline I have thought that I heard a client who had died & 0 & $0.0 \%$ \\
\hline
\end{tabular}


Table 2: Prevalence of grief-related reactions

\begin{tabular}{|c|c|c|c|c|c|}
\hline & & $n$ & mean & $\mathrm{sd}$ & $P$ value (t-test) ${ }^{*}$ \\
\hline 1 & $\begin{array}{l}\text { FEMALE staff } \\
\text { MALE staff }\end{array}$ & $\begin{array}{l}37 \\
28\end{array}$ & $\begin{array}{l}4.30 \\
2.36\end{array}$ & $\begin{array}{l}2.847 \\
2.765\end{array}$ & 0.004 \\
\hline 2 & $\begin{array}{l}<2 \text { Support Sources } \\
2 \text { or more Support Sources }\end{array}$ & $\begin{array}{l}28 \\
37\end{array}$ & $\begin{array}{l}2.25 \\
4.38\end{array}$ & $\begin{array}{l}2.533 \\
2.947\end{array}$ & 0.002 \\
\hline 3 & $\begin{array}{l}\text { Staff }<=44 \text { years } \\
\text { Staff }>44 \text { years }\end{array}$ & $\begin{array}{l}37 \\
28\end{array}$ & $\begin{array}{l}3.43 \\
3.50\end{array}$ & $\begin{array}{l}2.930 \\
3.037\end{array}$ & 0.537 \\
\hline 4 & $\begin{array}{l}\text { Small Caseload }<30 \\
\text { Large Caseload }>=30\end{array}$ & $\begin{array}{l}33 \\
32\end{array}$ & $\begin{array}{l}2.67 \\
4.28\end{array}$ & $\begin{array}{l}2.160 \\
3.438\end{array}$ & 0.016 \\
\hline 5 & $\begin{array}{l}<=5 \text { years Substance Misuse Experience } \\
>5 \text { years Substance Misuse Experience }\end{array}$ & $\begin{array}{l}24 \\
41\end{array}$ & $\begin{array}{l}2.96 \\
3.76\end{array}$ & $\begin{array}{l}2.941 \\
2.956\end{array}$ & 0.147 \\
\hline 6 & $\begin{array}{l}<=2 \text { Career DRDs } \\
>2 \text { Career DRDs }\end{array}$ & $\begin{array}{l}30 \\
35\end{array}$ & $\begin{array}{l}2.80 \\
4.03\end{array}$ & $\begin{array}{l}2.747 \\
3.044 \\
\end{array}$ & 0.047 \\
\hline 7 & $\begin{array}{l}<1 \text { yr since DRD } \\
>1 \text { yrs since DRD }\end{array}$ & $\begin{array}{l}34 \\
31\end{array}$ & $\begin{array}{l}3.79 \\
3.10\end{array}$ & $\begin{array}{l}3.102 \\
2.785 \\
\end{array}$ & 0.175 \\
\hline 8 & $\begin{array}{l}\text { Not at all close to client } \\
\text { Somewhat or very close to the client }\end{array}$ & $\begin{array}{l}11 \\
54\end{array}$ & $\begin{array}{l}2.09 \\
3.74\end{array}$ & $\begin{array}{l}2.343 \\
3.004\end{array}$ & 0.046 \\
\hline 9 & $\begin{array}{l}\text { Knew the deceased for }<1 \mathrm{yr} \\
\text { Knew the deceased for }>1 \mathrm{yr}\end{array}$ & $\begin{array}{l}32 \\
32\end{array}$ & $\begin{array}{l}3.31 \\
3.72\end{array}$ & $\begin{array}{l}2.429 \\
3.410\end{array}$ & 0.291 \\
\hline 10 & $\begin{array}{l}\text { Older DRD }>=35 \text { years } \\
\text { Younger DRD }<35 \text { years }\end{array}$ & $\begin{array}{l}22 \\
43\end{array}$ & $\begin{array}{l}3.59 \\
3.40\end{array}$ & $\begin{array}{l}2.987 \\
2.969\end{array}$ & 0.404 \\
\hline 11 & $\begin{array}{l}\text { DRD from other causes } \\
\text { DRD from accidental overdose }\end{array}$ & $\begin{array}{l}29 \\
36\end{array}$ & $\begin{array}{l}3.03 \\
3.81\end{array}$ & $\begin{array}{l}2.163 \\
3.454\end{array}$ & 0.138 \\
\hline
\end{tabular}

*Significant differences indicated by bold type 
Table 3: Predicting grief-related reactions

\begin{tabular}{llll}
\hline Linear Regression & \multicolumn{3}{l}{ Participants $(\mathrm{n}=59 *)$} \\
\cline { 2 - 4 } Predictors & $\mathrm{B}$ & $t$ & $p$ \\
\hline Full model & & & \\
Female staff (dummy coded, 0-1) & 0.5617 & 3.3825 & 0.0014 \\
Support Sources & 0.2160 & 3.2673 & 0.0019 \\
Months since DRD occurred (cubed) & 0.000004 & 2.8575 & 0.0061 \\
No. of DRDs on caseload (cubed) & 0.0001 & 0.6109 & 0.5439 \\
DRD from accidental overdose (dummy coded, 0-1) & -0.0753 & -0.4599 & 0.6475 \\
Constant & 0.4242 & 2.1388 & 0.0371 \\
& Adjusted $R^{2}=37.86 \%$ & \\
& $F=6.239, p=0.0001$ &
\end{tabular}

Model after variables indicating number of DRDs on caseload and DRDs from accidental overdose removed

Female staff (dummy coded, $0-1$ )

$\begin{array}{lll}0.4919 & 2.9877 & 0.0042 \\ 0.1983 & 3.0688 & 0.0033 \\ 3.59 \mathrm{E}-06 & 2.8726 & 0.0058 \\ 0.5027 & 2.4077 & 0.0194 \\ \text { Adjusted } R^{2}=33.01 \% & \\ F=8.093, p=0.0001 & \end{array}$

*Due to missing data in some of the included variables the sample size for regression analysis reduced from 65 to 59 